\title{
Optimization of Threshing Quality Control Strategy Based on Type-2 Fuzzy Logic Controller
}

\author{
Baoyan Xu, Xindong Ni, Yuan Wang, Yuxiang Wang, Yehong Liu, Xin Wang* \\ Beijing Key Laboratory of Optimized Design for Modern Agricultural Equipment, \\ College of Engineering, China Agricultural University (East Campus), \\ Beijing, China \\ wangxin117@cau.edu.cn
}

\begin{abstract}
At present, loss rate and grain damage are the most complicated problems for combine harvester. Besides, existing controllers that control threshing quality do not take into account environmental noise, data fluctuations, and other detection factors. In this paper, considering the interference of uncertain factors, a control strategy with low crashed rate and reduced loss rate using type-2 Fuzzy Logic Controller (FLC) is proposed. This control strategy takes threshing separation component as a research object and adopts combination of theory with experimental analysis. Firstly, basic data acquisition experiment of threshing system is designed. Secondly, a control strategy is established by adequately previous filled test data. In the process of control strategy design, Fuzzy Logic Toolbox evaluates the performance of type2 FLC. Integral of Square Error (ISE) and Integral of the Absolute value of the Error (IAE) show a better performance of type-2 FLC than of type-1 FLC. At last, field experiments are designed to verify the effectiveness of type-2 control strategy. The field test shows that the maximum reduction of grain damage rate and loss rate can reach to $44.08 \%$ and $29.6 \%$. Experiment results show that the type-2 FLC can significantly reduce loss rate, crashed rate, and improve threshing quality.
\end{abstract}

Index Terms-Fuzzy control; MATLAB; Combine harvester; Type-2 fuzzy logic.

\section{INTRODUCTION}

With the continuous increase of grain planting area, the demand for intelligent agricultural machinery is increasing rapidly [1]. As an essential intelligent machine, grain harvester reduces labor cost and improves harvesting efficiency [2], [3]. Typical grain harvester integrates collecting, cutting, threshing, separation, and other harvesting processes, of which threshing is the most crucial function [4]. Although combine harvesters are now widely used, the problem like grain loss and crashing, which are essential parameters for evaluating the threshing quality of combine harvesters, are still tricky.

With the development of sensing technology, computer measurement and control technology, the improvement of grain loss rate sensor and crashed rate sensor provides the

Manuscript received 3 August, 2019; accepted 23 January, 2020.

This research was funded under Grant (No. 2017YFD0700603) from the National Key Research and Development Program of China. possibility to monitor the threshing quality of combine harvester. X. L. Zhou et al. designed a grain loss rate sensor based on the piezoelectric effect [5]. J. F. Li et al. designed a PVDF - type grain loss virtual test system [6]. X. Chen et al. developed a grain crashed rate monitoring system on the ARM (Acorn RISC Machine) platform based on image processing technology [7]. M. Jahari et al. proposed a dualsource lighting scheme, which is applied on combine harvester grain crashed rate and impurity rate monitoring system providing hardware support for the monitoring of crashed rate and loss rate [8]. At the same time, researchers have designed many control algorithms to improve threshing quality. A grey prediction and type-1 fuzzy PID (Proportional, Integral, Derivative) control scheme for combine harvester forward speed to enhance threshing quality was proposed by J. H. Cui [9]. J. Chen [10] designed a type-1 fuzzy adaptive forward speed control system, which can decrease grain-crashed rate installed on combine harvester. Additionally, many mechanical improvements have been made based on experience to reduce the grain crashed rate and loss rate [11]-[14].

However, it should be pointed out that the existing literature on fuzzy control strategies for combine harvesters does not take into account the uncertainty of the environment and measurement data. Consequently, it is not reasonable to use an accurate membership function for measurement data without consideration of fluctuations and disturbances.

In order to improve the robustness of the threshing system, a control strategy with the standard of low damage rate and low loss rate is proposed based on type-2 FLC, which takes threshing separation components as the research object and adopts a combination of theory and experimental analysis. The validity of the model is verified through MATLAB simulation and field experiment.

\section{ACQUISITION OF BASIC DATA}

As it is known, the factors of the internal structure, working mechanism, and mathematical model of the controlled object are not considered carefully in the fuzzy control system. Therefore, a control model with operation 
and field experiments is established in this section.

\section{A. System Analysis}

When the roller rotates, threshing teeth penetrate grain crop in threshing clearance. High-speed threshing teeth with additional actions like compression, rubbing, and combing impact grain ears. Also, grain kernels are detached from stalks with acceleration function. The detachment process is shown in Fig. 1.

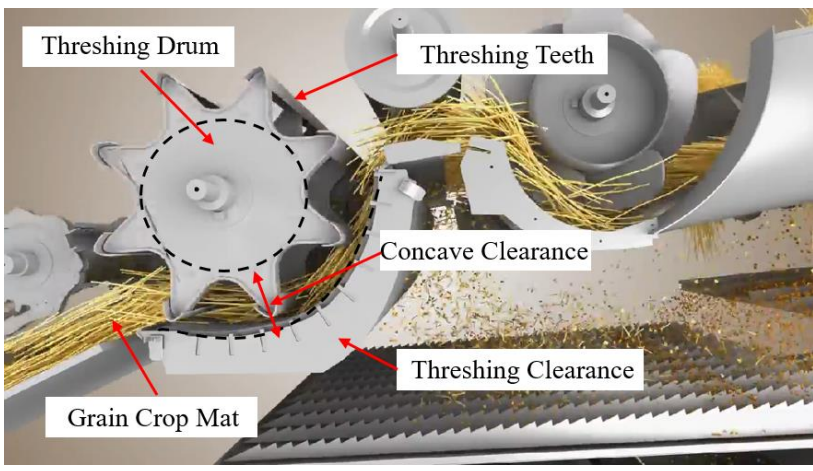

Fig. 1. Detachment process of grain kernels.

The threshing quality is affected by crop attribute parameters, feed quantity, and threshing system-operating parameters. In the actual operation, the crop attribute parameters, which consist of crop density, stem moisture content, and grain moisture content, are uncontrollable and cannot be monitored in real-time. Therefore, the threshing quality of combine harvesters can be adjusted only by roller speed and concave clearance, which constitute the basic sets of fuzzy control strategies.

\section{B. Design of Information Acquisition System}

The detection part of the threshing separation quality system on the combine harvester mainly consists of six parts: the crashed rate node, the loss rate node, the roller speed node, the concave clearance node, Industrial Personal Computer (IPC), and the data acquisition terminal. The loss rate node composed of a loss rate sensor, a CAN (Controller Area Network) communication node is installed at the exit of straw. The damage rate node installed in the granary sample collection room, is composed of an industrial camera and an IPC, and then the rolled speed node is composed of a Hall sensor and a CAN communication node. The concave clearance node is composed of electric push rods and a CAN communication node. The data acquisition terminal collects the data values of each node and stores them in the SD (Secure Digital) card. The communication with each node used CAN-Bus. The installation and composition of the hardware are shown in Fig. 2 and Fig. 3.

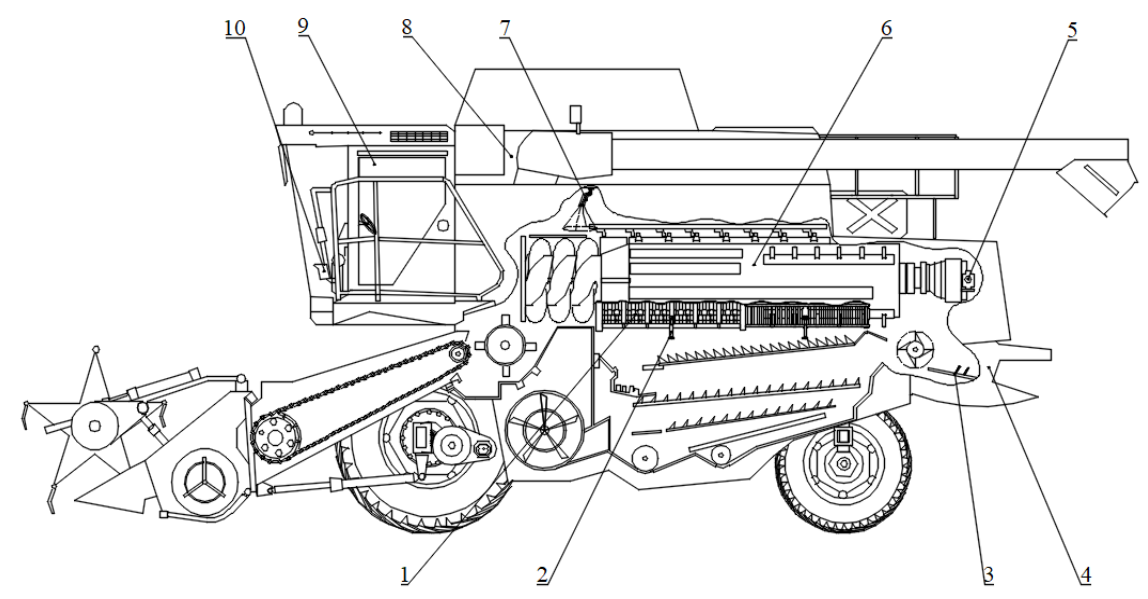

Fig. 2. Combine harvester information acquisition system diagram: 1 - Concave; 2 - Displacement sensor; 3 - Loss rate sensor; 4 - Straw; 5 - Hall sensor; 6 - Threshing roller; 7 - Industrial camera; 8 - Granary sample collection room; 9 - Cab; 10 - Data acquisition terminal.

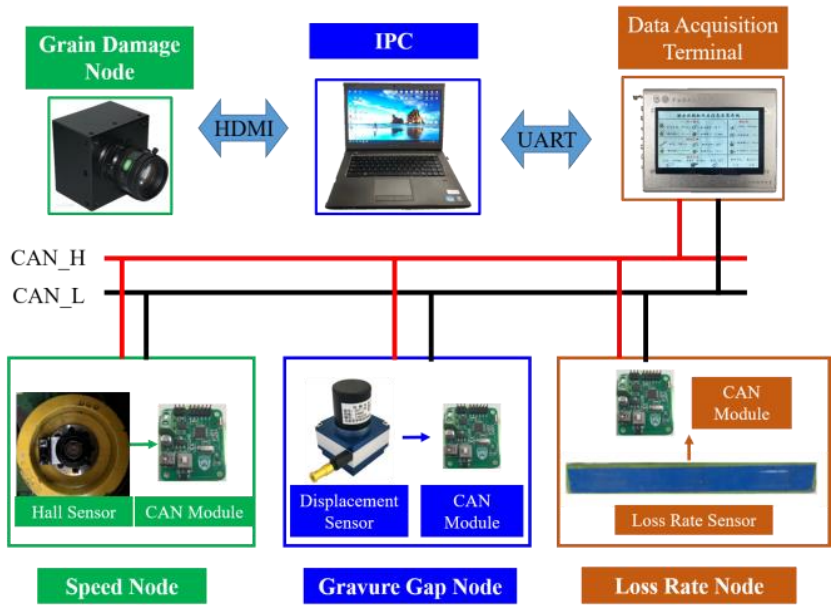

Fig. 3. Hardware Composition Diagram of Monitoring System.

\section{Field Experiment}

A Zoomlion TB60 combine harvester (nominal feeding amount - $6 \mathrm{~kg} / \mathrm{s}$, shearing and axial flow double roller threshing device, cutting width $-2.51 \mathrm{~m}$, productivity: $0.5 \div 1.25 \mathrm{hm}^{2} / \mathrm{h}$, supporting power $-92 \mathrm{~kW}$ ) is taken as the test prototype. The wheat variety is selected as Jingdong 22 with the average grain moisture content of $7.90 \%$ and the average stem moisture content of $8.04 \%$. The field harvesting experiments were conducted at the National Precision Agricultural Demonstration Base in Xiaotangshan, Beijing. According to the national standard GB/T 80972008 "Equipment for harvesting - Combine harvesters - Test procedure" [15], the test field should be flat with no other sundries, the crops grow evenly with no lodging and weeds as shown in Fig. 4. 


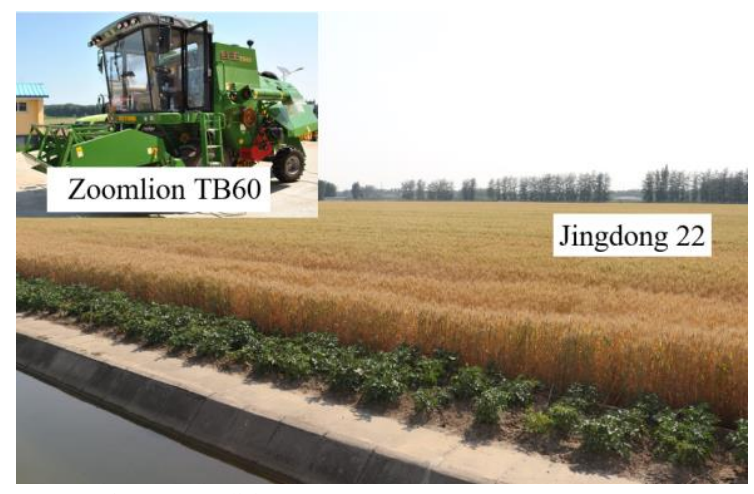

Fig. 4. Experiment conditions.

\section{Experiment Result}

In the field experiment, concave clearance is set at $10 \mathrm{~mm}, 15 \mathrm{~mm}$, and $20 \mathrm{~mm}$, respectively, and the speed range of roller speed is controlled at $750 \mathrm{r} / \mathrm{min}-1200 \mathrm{r} / \mathrm{min}$. According to the national standard GB/T 8097-2008 "Equipment for harvesting - Combine harvesters - Test procedure" [15], the relationship between concave clearance, roller speed, and threshing quality is shown in Fig. 5.

\section{TYPE-2 FUZZY LOGIC SYSTEMS}

As an extension of the concept of type-1 fuzzy set [16], L. A. Zadeh introduced Type-2 Fuzzy System (T2FS) [17]. The membership grade for every element of type-2 is a fuzzy set in $[0,1]$, unlike a type- 1 , where the membership grade is a crisp number in $[0,1]$ [18]. Dynamic errors and uncertainties are allowed to be introduced on account of the uncertainty of T2FS membership functions. Therefore, T2FS offers better capabilities to handle uncertainties involving the environment, linguistic, measured data, etc.

\section{A. Type-2 Fuzzy Sets}

A type-2 fuzzy set $\tilde{\mathrm{A}}$ is characterized by a type-2 membership function $\mu_{\tilde{\mathrm{A}}}(x, u)$, where $x \in \mathrm{X}$ and $u$ $\in \mathrm{J}_{x} \subseteq[0,1]$, i.e.

$$
\tilde{\mathrm{A}}=\left\{\left((x, u), \mu_{\tilde{\mathrm{A}}}(x, u)\right) \mid \forall x \in \mathrm{X}, \forall u \in \mathrm{J}_{\mathrm{x}} \subseteq[0,1]\right\},
$$

where $0 \leq \mu_{\tilde{\mathrm{A}}}(x, u) \leq 1, x$ is the primary membership, and $\mu_{\tilde{\mathrm{A}}}(x, u)$ is a type-1 fuzzy set known as the secondary set [19]-[21]. Actually, secondary membership functions are the membership function values for each point of the primary membership function [21].

In the Cartesian coordinate system, the secondary set $\mu_{\tilde{\mathrm{A}}}(x, u)$ of the type-2 fuzzy set $\tilde{\mathrm{A}}$ can be expressed as a 2-D region, which is called the footprint of uncertainty (FOU). It is the union of all primary memberships. The upper membership function $\bar{\mu}_{\tilde{A}}(x)$ and lower membership function $\bar{\mu}_{\tilde{\mathrm{A}}}(x)$ are the boundary of FOU (see Fig. 6). $\bar{\mu}_{\tilde{\mathrm{A}}}(x)$ and $\underline{\mu}_{\tilde{A}}(x)$ can be characterized as follows [22]:

$$
\begin{gathered}
\bar{\mu}_{\tilde{\mathrm{A}}}(\mathrm{x})=\sup \left\{u \mid u \in[0,1], \mu_{\tilde{\mathrm{A}}}(\mathrm{x}, \mathrm{u})>0\right\}, \\
\underline{\mu}_{\tilde{\mathrm{A}}}(\mathrm{x})=\inf \left\{u \mid u \in[0,1], \mu_{\tilde{\mathrm{A}}}(\mathrm{x}, \mathrm{u})>0\right\} .
\end{gathered}
$$

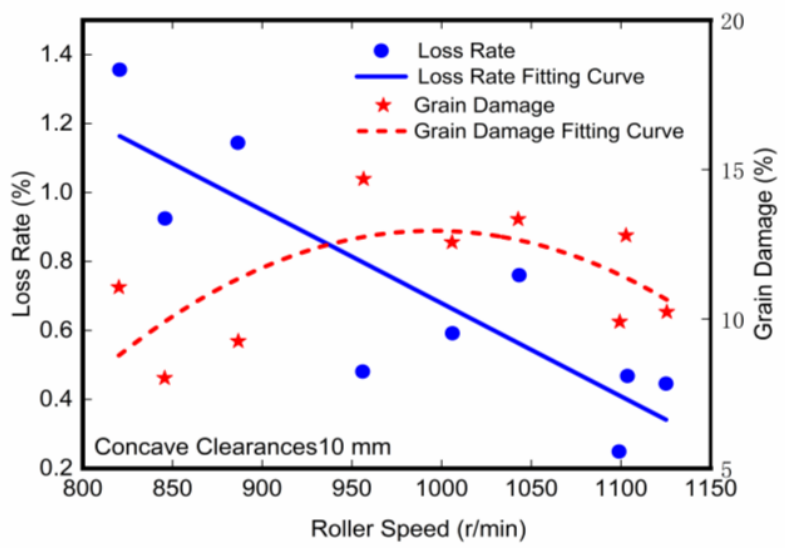

(a)

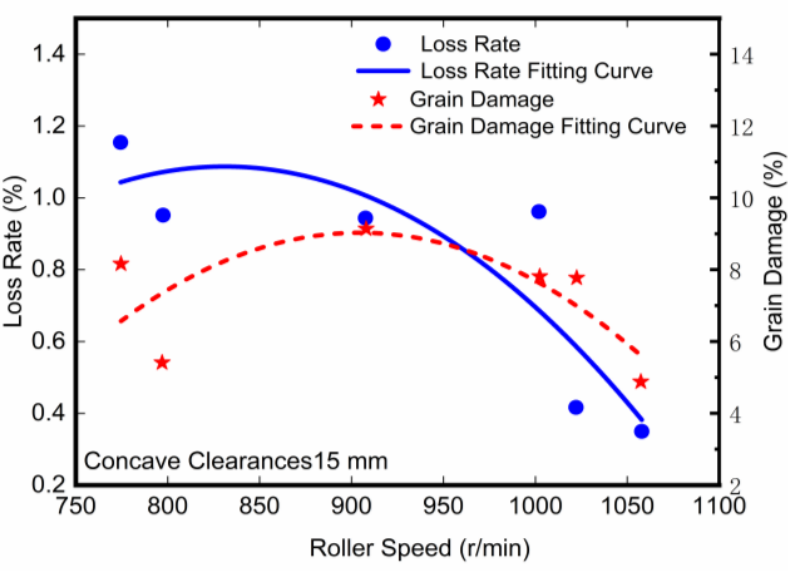

(b)

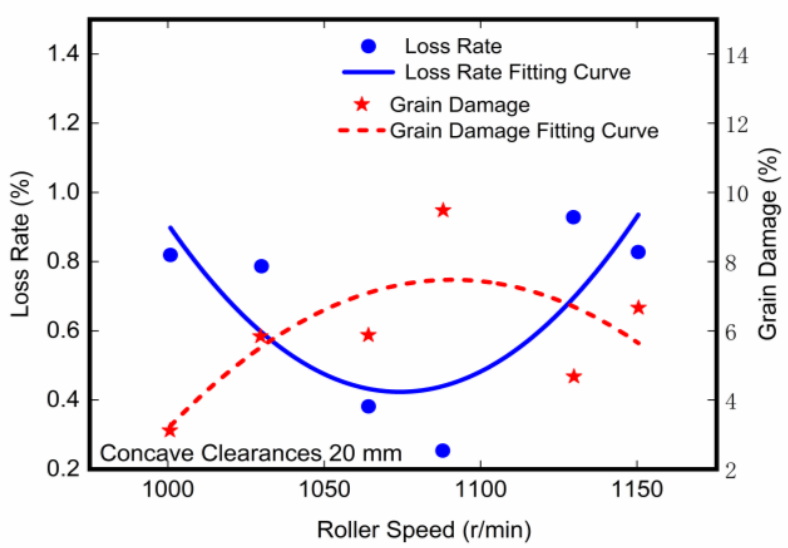

(c)

Fig. 5. Experiment result of basic test: a) concave clearance is $10 \mathrm{~mm}$; b) concave clearance is $15 \mathrm{~mm}$; c) concave clearance is $20 \mathrm{~mm}$.

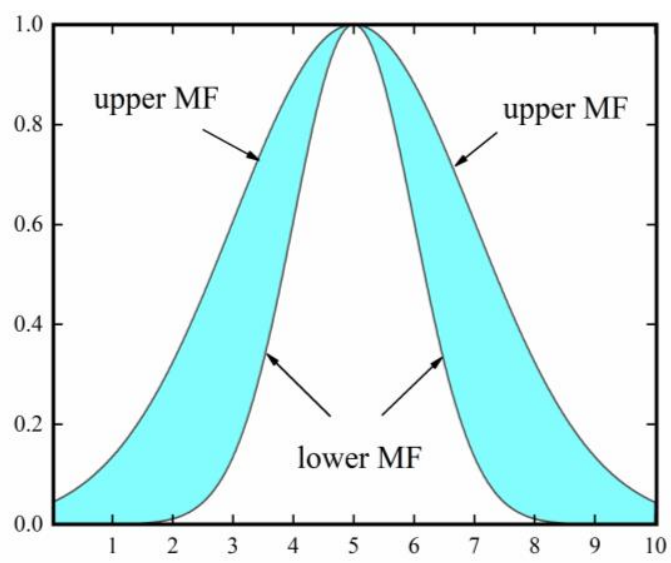

Fig. 6. Upper and lower membership function. 


\section{B. Structure of a Type-2 Fuzzy Logic Systems}

A general structure of a type-2 fuzzy logic system is shown in Fig. 7. Similar to the type-1 fuzzy system structure, the type-2 fuzzy system is composed of four sections: the fuzzifier, rules based on experience and knowledge, inference engine, and defuzzification.

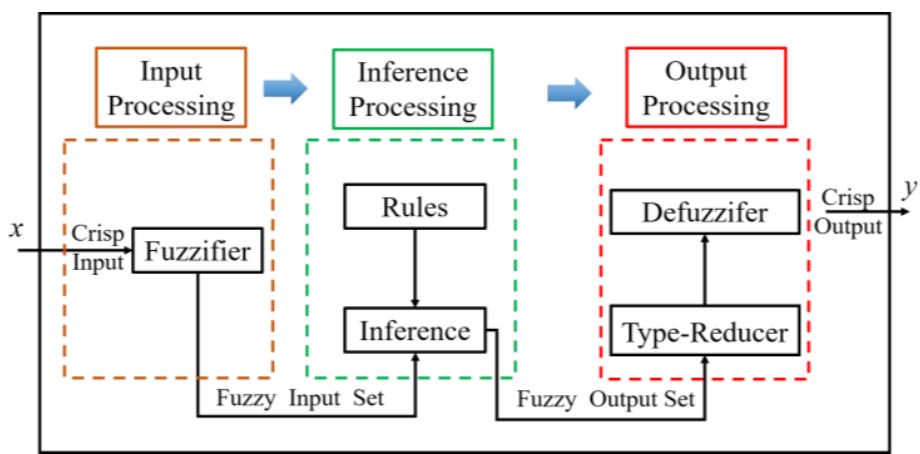

Fig. 7. Structure of a general type-2 fuzzy system [23].

The crisp inputs are transformed into fuzzy subsets by fuzzifier. During the fuzzification process, the number and membership functions of fuzzy subsets covering the fuzzy universe are determined. Fuzzy rules are regarded as the core of a fuzzy controller, which is equivalent to the correction device or the traditional control system. There are two methods to generate fuzzy control rules. One is based on the actual operating experience and knowledge of the operator, the other one is based on the input-output data of the system. The inference block is activated when crisp inputs are fuzzified into fuzzy input sets. Input type-2 fuzzy sets are mapped to output type- 2 fuzzy sets by the inference engine according to fuzzy rules, and calculate the union and intersection of type-2 fuzzy sets based on the compositions of type-2 relations [24].

However, the difference between type-1 fuzzy system and type-2 fuzzy system is the output processing part. Compared to type-1 fuzzy system, "type-reducer" processing is included in type-2 fuzzy system. After type reduction, type-2 fuzzy sets, which are exported by the inference processing, are converted to type-1 fuzzy sets. Then, the crisp output is obtained by the defuzzifier.

For the threshing quality control strategy of combine harvester based on type- 2 fuzzy control, the crisp input of the system is controllable factors, such as roller speed and concave clearance. The process of assigning membership functions and intervals to system input variables is the fuzziness of the system. The process of assigning membership functions and intervals to system output variables is defuzzification. The process of building fuzzy rules between input variables and output variables is an inference process.

\section{DESIGN OF THRESHING QUALITY CONTROLLER}

\section{A. Design of Low Grain Damage Control Strategy}

\section{Membership functions and sets of grain damage FLC}

The implementation of the grain damage rate fuzzy controller in terms of type-2 FLC sets has two input variables, which are the concave clearances $x_{1}\left(x_{1} \in \tilde{\mathrm{X}}_{1}\right)$ and damage rate $x_{2}\left(x_{2} \in \tilde{\mathrm{X}}_{2}\right)$, and one output $y_{1}\left(y_{1} \in \tilde{\mathrm{Y}}_{1}\right)$, which is the linear velocity of the threshing roller. For each of the inputs and outputs of the type-2 FLC, Gaussian membership functions (MFs) were selected. The type-2 Gaussian MFs with a fixed centre, $c$, and an uncertain standard deviation, $\sigma$, i.e.

$$
\mu_{\mathrm{A}}(x)=e^{-(x-c)^{2} / 4 \sigma^{2}} .
$$

In terms of (2) and (3), for each of inputs of the type-2 FLC, $\bar{\mu}_{\tilde{\mathrm{A}}}(x)$ and $\underline{\mu}_{\tilde{\mathrm{A}}}(x)$ can be characterized as below [25]:

$$
\begin{aligned}
& \bar{\mu}_{\tilde{\mathrm{A}}}(x)=\mathrm{N}\left(c, \sigma_{2} ; x\right) \equiv e^{-(x-c)^{2} / 4 \sigma_{2}{ }^{2}}, \\
& \underline{\mu}_{\tilde{\mathrm{A}}}(x)=\mathrm{N}\left(c, \sigma_{1} ; x\right) \equiv e^{-(x-c)^{2} / 4 \sigma_{1}{ }^{2}} .
\end{aligned}
$$

The input set, concave clearances $\tilde{X}_{1}$, is defined by three type-2 fuzzy Gaussian MFs (SG, MG, and LG) in the interval from 10 to 20 as illustrated in Fig. 8(a). The other input set, damage rate $\tilde{X}_{2}$, is defined by three MFs (ND, $\mathrm{MD}$, and LD) in the interval from 3.5 to 8 as illustrated in Fig. 8(b). The output sets, the linear velocity of the threshing roller $\tilde{\mathrm{Y}}_{1}$, is defined by five MFs (MI, SV, MV, LV, and MA) in the interval from 800 to 1200 as illustrated in Fig. 8 (c). The characteristics of the inputs and output sets of the grain damage rate fuzzy controller are shown in Table I.

TABLE I. CHARACTERISTICS OF THE INPUTS AND OUTPUT OF GRAIN DAMAGE TYPE-2 FLC.

\begin{tabular}{|c|c|c|c|c|}
\hline \multirow{4}{*}{ Variable } & Term & $\begin{array}{c}\text { Centre } \\
c\end{array}$ & $\begin{array}{c}\text { Standard } \\
\text { deviation } \\
\sigma_{1}\end{array}$ & $\begin{array}{c}\text { Standard } \\
\text { deviation } \\
\sigma_{2}\end{array}$ \\
\hline \multirow{4}{*}{ Input $x_{l}$} & SG & 10 & 1.432 & 2.124 \\
\cline { 2 - 5 } & $\mathrm{MG}$ & 15 & 1.432 & 2.124 \\
\cline { 2 - 5 } & $\mathrm{LG}$ & 20 & 1.432 & 2.124 \\
\hline \multirow{3}{*}{ Input $x_{2}$} & $\mathrm{ND}$ & 3.5 & 0.624 & 0.956 \\
\cline { 2 - 5 } & $\mathrm{MD}$ & 5.75 & 0.624 & 0.956 \\
\cline { 2 - 5 } & $\mathrm{LD}$ & 8 & 0.624 & 0.956 \\
\hline \multirow{5}{*}{ Output $y_{1}$} & $\mathrm{MI}$ & 800 & 30.562 & 42.465 \\
\cline { 2 - 5 } & $\mathrm{SV}$ & 900 & 30.562 & 42.465 \\
\cline { 2 - 5 } & $\mathrm{MV}$ & 1000 & 30.562 & 42.465 \\
\cline { 2 - 5 } & $\mathrm{LV}$ & 1100 & 30.562 & 42.465 \\
\cline { 2 - 5 } & $\mathrm{MA}$ & 1200 & 30.562 & 42.465 \\
\hline
\end{tabular}




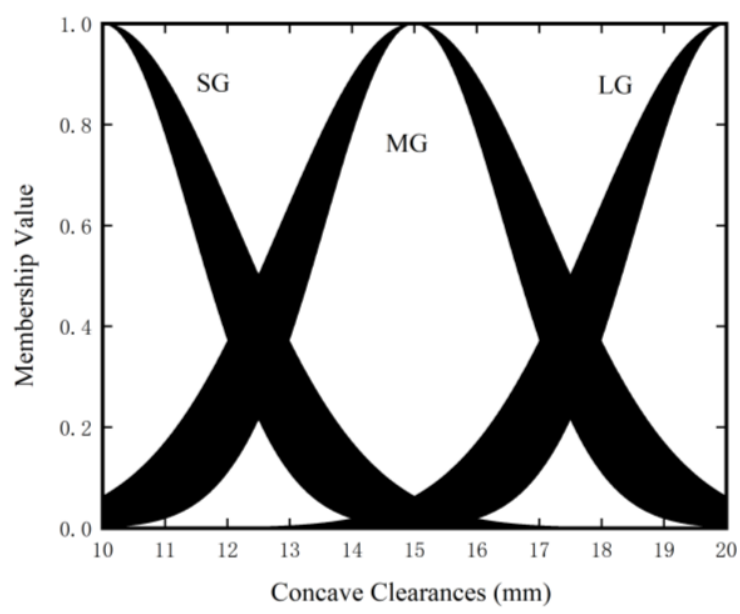

(a)

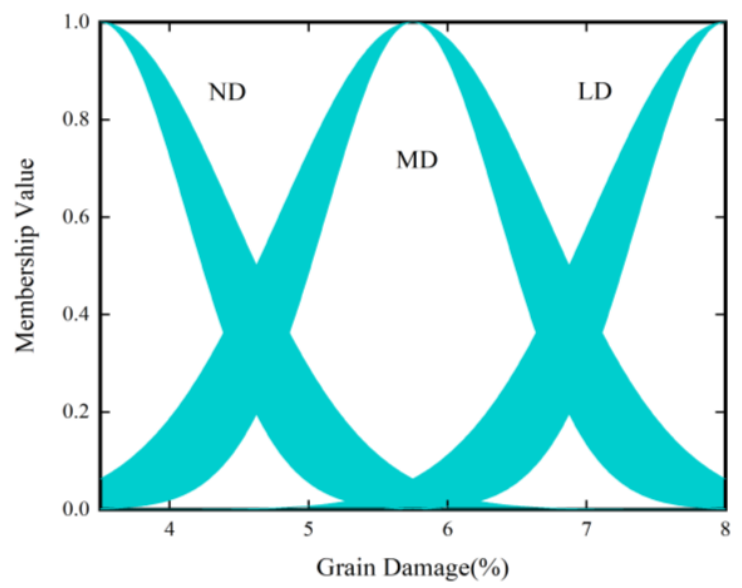

(b)

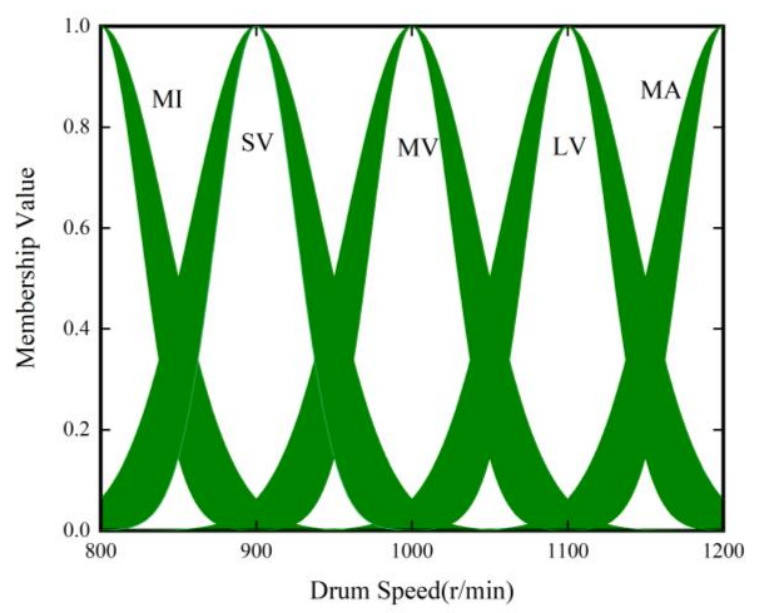

(c)

Fig. 8. Membership function: a) Input $x_{1}$ membership function; b) Input $x_{2}$ membership function; c) Output $y_{1}$ membership function.

\section{Fuzzy rules of grain damage FLC}

Rules are the basis for designing fuzzy controllers. For a type-2 FLS, with $n$ inputs $x_{1} \in \mathrm{X}_{1}, \ldots, x_{n} \in \mathrm{X}_{\mathrm{n}}$ and one output $y \in \mathrm{Y}$. Assuming that a Multiple Input Single Output (MISO) has M rules, then $k^{\text {th }}$ rules can be expressed as [25]

$$
\begin{gathered}
R^{k} \text { :If } x_{1} \text { is } \tilde{F_{1}^{k}} \text { and ...and } x_{n} \text { is } \tilde{F_{1}^{k}}, \\
\text { then } y \text { is } \tilde{Y^{k}}, k=1, \ldots, M .
\end{gathered}
$$

According to experimental data and (7), rules of grain damage FLC are established:

$-\mathrm{R}^{1}$ : IF $x_{1}$ is SG and $x_{2}$ is ND, THEN $y_{1}$ is MI;

$-\mathrm{R}^{2}$ : IF $x_{1}$ is MG and $x_{2}$ is ND, THEN $y_{1}$ is LV;

$-\mathrm{R}^{3}$ : IF $x_{1}$ is LG and $x_{2}$ is ND, THEN $y_{1}$ is LV;

$-\mathrm{R}^{4}$ : IF $x_{1}$ is $\mathrm{SG}$ and $x_{2}$ is MD, THEN $y_{1}$ is MI;

$-\mathrm{R}^{5}$ : IF $x_{1}$ is MG and $x_{2}$ is MD, THEN $y_{1}$ is MV;

$-\mathrm{R}^{6}$ : IF $x_{1}$ is LG and $x_{2}$ is MD, THEN $y_{1}$ is MV;

$-\mathrm{R}^{7}$ : IF $x_{1}$ is SG and $x_{2}$ is LD, THEN $y_{1}$ is SV;

$-\mathrm{R}^{8}$ : IF $x_{1}$ is MG and $x_{2}$ is LD, THEN $y_{1}$ is $\mathrm{SV}$;

$-\mathrm{R}^{9}$ : IF $x_{1}$ is $\mathrm{LG}$ and $x_{2}$ is $\mathrm{LD}$, THEN $y_{1}$ is $\mathrm{LV}$.

\section{B. Design of Low Loss Rate Control Strategy}

1. Membership functions and sets of loss rate FLC

There are two input variables, which are concave clearances $x_{3}\left(x_{3} \in \tilde{X}_{3}\right)$ and loss rate $x_{4}\left(x_{4} \in \tilde{X}_{4}\right)$, and one output $y_{2}\left(y_{2} \in \tilde{Y}_{2}\right)$, which is the linear velocity of the threshing roller in the loss rate FLC. The fuzzy method of the loss rate FLC is similar to grain damage FLC. In loss rate FLS, the input set $\tilde{X}_{4}$ is defined by three MFs, which are SL, ML, and LL in the interval [0.25 0.6] as illustrated in Fig. 9. In addition, $\tilde{X}_{3}$ and $\tilde{Y}_{2}$ are equal to sets $\tilde{X}_{1}$ and $\tilde{Y}_{1}$ separately. The characteristics of the sets in the loss rate FLC are showed in Table II.

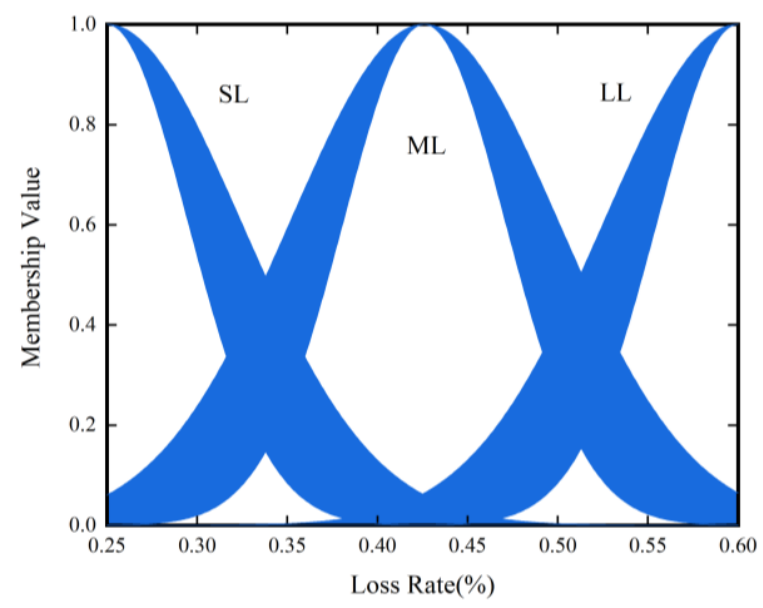

Fig. 9. Input $x_{4}$ membership function for the loss rate type-2 FLC.

TABLE II. CHARACTERISTICS OF THE INPUTS AND OUTPUT OF

\begin{tabular}{|c|c|c|c|c|}
\hline \multirow{4}{*}{ Variable } & Term & $\begin{array}{c}\text { Centre } \\
c\end{array}$ & $\begin{array}{c}\text { Standard } \\
\text { deviation } \\
\sigma_{1}\end{array}$ & $\begin{array}{c}\text { Standard } \\
\text { deviation } \\
\sigma_{2}\end{array}$ \\
\hline \multirow{3}{*}{ Input $x_{3}$} & SG & 10 & 1.432 & 2.124 \\
\cline { 2 - 5 } & $\mathrm{MG}$ & 15 & 1.432 & 2.124 \\
\cline { 2 - 5 } Input $x_{4}$ & $\mathrm{LG}$ & 20 & 1.432 & 2.124 \\
\hline & $\mathrm{SL}$ & 0.250 & 0.0450 & 0.07432 \\
\cline { 2 - 5 } & $\mathrm{ML}$ & 0.426 & 0.0450 & 0.07432 \\
\cline { 2 - 5 } & $\mathrm{LL}$ & 0.600 & 0.0450 & 0.07432 \\
\hline \multirow{5}{*}{ Output $y_{2}$} & $\mathrm{MI}$ & 800 & 30.562 & 42.465 \\
\cline { 2 - 5 } & $\mathrm{SV}$ & 900 & 30.562 & 42.465 \\
\cline { 2 - 5 } & $\mathrm{MV}$ & 1000 & 30.562 & 42.465 \\
\cline { 2 - 5 } & $\mathrm{LV}$ & 1100 & 30.562 & 42.465 \\
\cline { 2 - 5 } & $\mathrm{MA}$ & 1200 & 30.562 & 42.465 \\
\hline
\end{tabular}




\section{Fuzzy rules of loss rate FLC}

According to experimental data and (7), the rules of loss rate FLC can be obtained:

$-\mathrm{R}^{1}$ : IF $x_{3}$ is SG and $x_{4}$ is ND, THEN $y_{2}$ is MI;

$-\mathrm{R}^{2}$ : IF $x_{3}$ is MG and $x_{4}$ is ND, THEN $y_{2}$ is LV;

$-\mathrm{R}^{3}$ : IF $x_{3}$ is LG and $x_{4}$ is ND, THEN $y_{2}$ is LV;

$-\mathrm{R}^{4}$ : IF $x_{3}$ is $\mathrm{SG}$ and $x_{4}$ is MD, THEN $y_{2}$ is $\mathrm{SV}$;

$-\mathrm{R}^{5}$ : IF $x_{3}$ is MG and $x_{4}$ is MD, THEN $y_{2}$ is SV;

$-\mathrm{R}^{6}$ : IF $x_{3}$ is LG and $x_{4}$ is MD, THEN $y_{2}$ is MA;

$-\mathrm{R}^{7}$ : IF $x_{3}$ is $\mathrm{SG}$ and $x_{4}$ is LD, THEN $y_{2}$ is MV;

$-\mathrm{R}^{8}$ : IF $x_{3}$ is MG and $x_{4}$ is LD, THEN $y_{2}$ is MI;

$-\mathrm{R}^{9}$ : IF $x_{3}$ is LG and $x_{4}$ is LD, THEN $y_{2}$ is LV.

\section{SimULATION OF THRESHING QUALITY CONTROLLER}

To test the controller designed in Section III, type-1 FLC is designed and compared with type-2 fuzzy FLC by the use of Fuzzy Toolbox reused from MATLAB commercial Fuzzy Logic Toolbox [26]. The primary operations in Fuzzy Toolbox include editing fuzzy inference rules, selecting and setting membership functions, inference and observation. Moreover, to evaluate the response of the strategy, the criteria ISE and IAE involved in [25] are used in this section. ISE and IAE can be expressed as:

$$
\begin{gathered}
\mathrm{ISE}=\int_{0}^{\infty}[e(t)]^{2} d t, \\
\mathrm{IAE}=\int_{0}^{\infty}|e(t)| d t .
\end{gathered}
$$

\section{A. Simulation of Grain Damage Control Strategy}

\section{Design of type-1 FLC of grain damage}

For the inputs of the grain damage type-1 FLC, three type1 fuzzy Gaussian MFs of concave clearances are defined as SG1-T1, MG1-T1, and LG1-T1. The universe and centers for these membership functions are same to type-2 FLC. In addition, their standard deviations are 2.124. Other inputs, the MFs of grain damage, are defined as ND1-T1, MD1-T1, and LD1-T1. The universe and centers of grain damage are the same as type-2 FLC, and the standard deviation of type- 1 grain damage is 0.956 .

For the output of grain damage type-1 FLC, roller speed, five type-1 fuzzy Gaussian MFs are defined as MI-T1, SVT1, MV-T1, LV-T1, and MA-T1. The characteristics of type-1 MFs of inputs and output are illustrated in Table III.
TABLE III. CHARACTERISTICS OF THE INPUTS AND OUTPUT OF GRAIN DAMAGE TYPE-1 FLC

\begin{tabular}{|c|c|c|c|}
\hline \multirow{3}{*}{ Variable } & Term & $\begin{array}{c}\text { Centre } \\
c\end{array}$ & $\begin{array}{c}\text { Standard deviation } \\
\sigma_{1}\end{array}$ \\
\hline \multirow{3}{*}{ Input $x_{5}$} & SG1-T1 & 10 & 2.124 \\
\cline { 2 - 4 } & MG1-T1 & 15 & 2.124 \\
\cline { 2 - 4 } Input $x_{6}$ & LG1-T1 & 20 & 2.124 \\
\hline & ND1-T1 & 3.5 & 0.956 \\
\cline { 2 - 4 } & MD1-T1 & 5.75 & 0.956 \\
\cline { 2 - 4 } & LD1-T1 & 8 & 0.956 \\
\hline \multirow{5}{*}{ Output $y_{3}$} & MI1-T1 & 800 & 42.465 \\
\cline { 2 - 4 } & SV1-T1 & 900 & 42.465 \\
\cline { 2 - 4 } & MV1-T1 & 1000 & 42.465 \\
\cline { 2 - 4 } & LV1-T1 & 1100 & 42.465 \\
\cline { 2 - 4 } & MA1-T1 & 1200 & 42.465 \\
\hline
\end{tabular}

\section{Simulation of grain damage control strategy}

According to the previous description, Type-1 FLCs and type-2 FLCs of grain damage are built in the Fuzzy Inference Editor of MATLAB.

When the values of concave clearance are $10 \mathrm{~mm}, 15 \mathrm{~mm}$, and $20 \mathrm{~mm}$ separately, the linear velocity of the roller varies with the grain damage as shown in Figs. 10(a)-10(c).

There is always an error between the outputs of FLCs and fitting curves on account of the open-loop system. However, the trend between them is consistent. Table IV shows the values of ISE and IAE for the grain damage FLCs.

TABLE IV. COMPARISON OF GRAIN DAMAGE PERFORMANCE CRITERIA ISE AND IAE FOR TYPE-1 AND TYPE-2 FLC.

\begin{tabular}{|c|c|c|c|}
\hline $\begin{array}{c}\text { Concave } \\
\text { Clearances(mm) }\end{array}$ & Term & Type-1 FLC & Type-2 FLC \\
\hline \multirow{2}{*}{10} & ISE & 2521.3 & 875.2 \\
\cline { 2 - 4 } & IAE & 459.21 & 58.09 \\
\hline \multirow{2}{*}{15} & ISE & 410.2 & 395.6 \\
\cline { 2 - 4 } & IAE & 132.1 & 120.6 \\
\hline \multirow{2}{*}{20} & ISE & 2301.1 & 1871.9 \\
\cline { 2 - 4 } & IAE & 420.1 & 213.5 \\
\hline
\end{tabular}

As can be seen from Table IV, ISE and IAE of type-2 FLCs are less than that of type-1 FLCs. These values indicate a better performance of the type- 2 grain damage FLC designed in section III than of type-1 FLC, because the type-2 FLC has a good adaptability to the error tolerance rate.

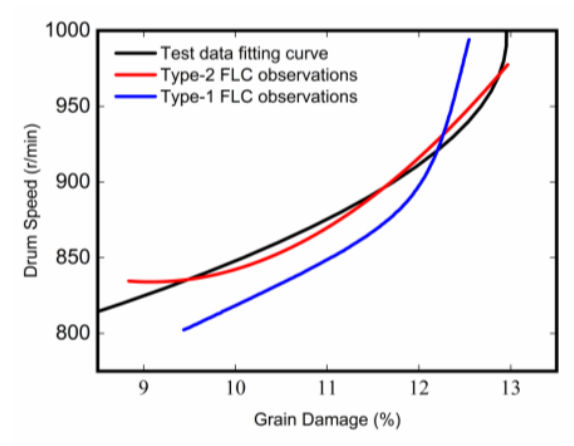

(a)

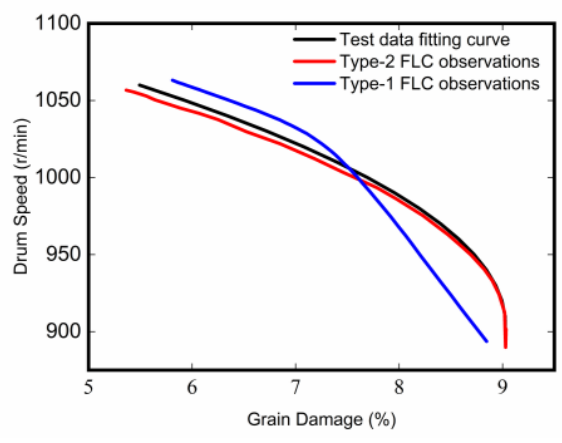

(b)

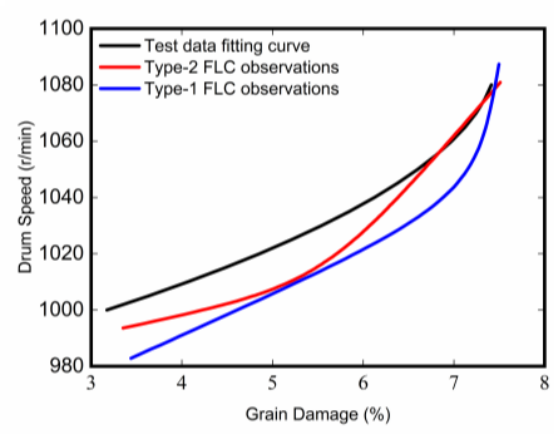

(c)

Fig. 10. The response of type-1 FLC and type-2 FLC of grain damage control strategies: a) concave clearances is $10 \mathrm{~mm}$; b) concave clearances is $15 \mathrm{~mm}$; c) concave clearances is $20 \mathrm{~mm}$. 


\section{B. Simulation of Loss Rate Control Strategy}

\section{Design of type-1 FLC of loss rate}

The simulation comparison method is used to evaluate the type-2 control strategy for the loss rate in this section.

For the inputs of the type-1 loss rate FLC, three type-1 fuzzy Gaussian MFs of loss rate are defined as SL2-T1, ML2-T1, and LL2-T1. The universe and centers for these membership functions are same as type-2 FLC. Also, their standard deviation is 0.07432. Other inputs, the MFs of concave clearance, are defined as SG2-T1, MG2-T1, and LG2-T1. Table V lists the characteristics of the MFs of the loss rate type-1 FLC sets.

When the values of the concave clearances are $10 \mathrm{~mm}$, $15 \mathrm{~mm}$, and $20 \mathrm{~mm}$, the responses of the loss rate FLC are shown in Figs. 11(a)-11(c) separately. Then, the performance criteria ISE and IAE are shown in Table VI.
TABLE V. CHARACTERISTICS OF THE INPUTS AND OUTPUT OF LOSS RATE TYPE-1 FLC.

\begin{tabular}{|c|c|c|c|}
\hline \multirow{4}{*}{ Variable } & Term & $\begin{array}{c}\text { Centre } \\
c\end{array}$ & $\begin{array}{c}\text { Standard } \\
\text { deviation } \\
\sigma_{1}\end{array}$ \\
\hline \multirow{4}{*}{ Input $x_{7}$} & SG2-T1 & 10 & 2.124 \\
\cline { 2 - 4 } & MG2-T1 & 15 & 2.124 \\
\cline { 2 - 4 } & LG2-T1 & 20 & 2.124 \\
\hline \multirow{3}{*}{ Input $x_{8}$} & SL2-T1 & 0.250 & 0.07432 \\
\cline { 2 - 4 } & ML2-T1 & 0.426 & 0.07432 \\
\cline { 2 - 4 } & LL2-T1 & 0.600 & 0.07432 \\
\hline \multirow{5}{*}{ Output $y_{4}$} & MI2-T1 & 800 & 42.465 \\
\cline { 2 - 4 } & SV2-T1 & 900 & 42.465 \\
\cline { 2 - 4 } & MV2-T1 & 1000 & 42.465 \\
\cline { 2 - 4 } & LV2-T1 & 1100 & 42.465 \\
\cline { 2 - 4 } & MA2-T1 & 1200 & 42.465 \\
\hline
\end{tabular}

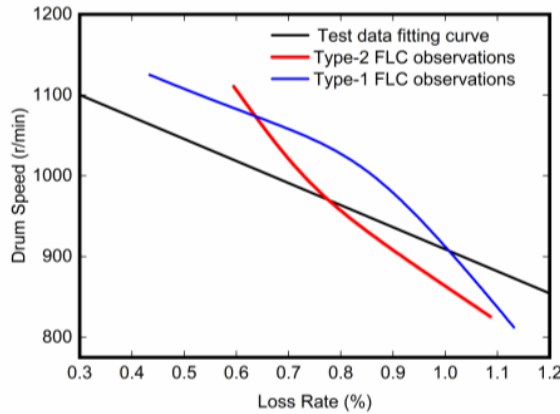

(a)

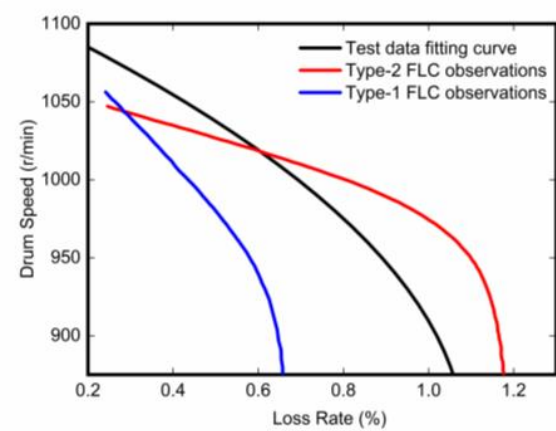

(b)

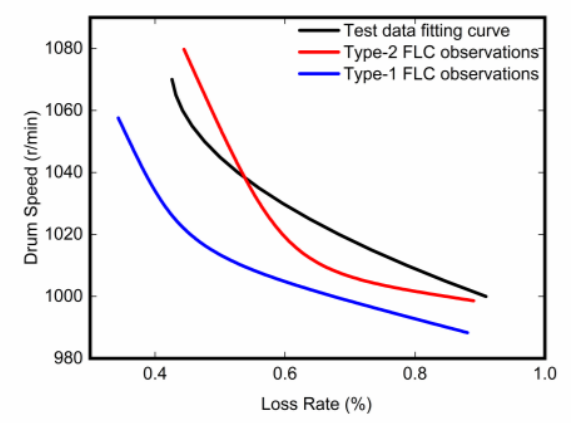

(c)

Fig. 11. The response of type-1 FLC and type-2 FLC of loss rate control strategies: a) Concave clearance is $10 \mathrm{~mm}$; b) Concave clearance is $15 \mathrm{~mm}$; c) Concave clearance is $20 \mathrm{~mm}$.

TABLE VI. COMPARISON OF LOSS RATE PERFORMANCE CRITERIA ISE AND IAE FOR TYPE-1 AND TYPE-2 FLC.

\begin{tabular}{|c|c|c|c|}
\hline $\begin{array}{c}\text { Concave } \\
\text { clearances }(\mathbf{m m})\end{array}$ & Term & Type-1 FLC & Type-2 FLC \\
\hline \multirow{2}{*}{10} & ISE & 7825.6 & 2146.9 \\
\cline { 2 - 4 } & IAE & 1093.7 & 542.1 \\
\hline \multirow{2}{*}{15} & ISE & 17256.3 & 1850.2 \\
\cline { 2 - 4 } & IAE & 2165.8 & 214.5 \\
\hline \multirow{2}{*}{20} & ISE & 1424.1 & 547.1 \\
\cline { 2 - 4 } & IAE & 304.2 & 142.1 \\
\hline
\end{tabular}

From Table VI, when the concave clearance is $10 \mathrm{~mm}$, ISE and IAE of type-2 FLC are $27.43 \%$ and $49.56 \%$ of type-1 FLC separately. The proportions are $10.7 \%$ and $9.9 \%$ under the condition that the concave clearance is $15 \mathrm{~mm}$. When the concave clearance is $20 \mathrm{~mm}$, the proportions are $38.4 \%$ and $46.7 \%$. The proportions indicate a better performance of the type-2 FLCs than of type-1 FLCs.

\section{FIELD EXPERIMENT}

\section{A. Design of Field Experiment}

In order to verify the effectiveness of control strategy based on type-2 fuzzy logic controller, field experiment is designed in this section. The field experiment is divided into two parts: control experiment and uncontrolled experiment. First, select the expected loss rate and crushing rate according to GB/T 8097-2008 "Equipment for harvesting combine harvesters - Test procedure". Then, the speed of the drum is calculated according to concave clearance of harvester and fuzzy logic controller.

In the control experiment, the speed of the drum is calculated based on the type-2 fuzzy logic controller designed in Section IV. In the uncontrolled experiment, the speed of the drum is calculated based on the type-1 fuzzy logic controller designed in section $\mathrm{V}$. Then, the speed of the drum is adjusted to the calculated value of the model through the manual throttle, and then the operation is started. Average grain crashed rate and loss rates are calculated by breakage rate sensor and loss rate sensor, separately.

In order to ensure the same feed quantity in the control experiment and uncontrolled experiment, the harvesting speed was kept basically the same. In addition, the plots with the same average crop density, average stem water content, and average grain water content were selected.

\section{B. Experiment and Analysis of Experiment Results}

According to the national standard GB/T 8097-2008 "Equipment for harvesting - Combine harvesters - Test procedure" [15], the experiment was carried out in Beijing National Precision Agricultural Demonstration Base on June 25, 2018 as shown in Fig. 12. The experiment conditions are shown in Table VII.

The experiment results of loss rate and crashed rate are shown in Fig. 13 and Fig. 14 separately. On the premise that 
the concave clearance is set as $10 \mathrm{~mm}$ or $15 \mathrm{~mm}$, the speed is set as $900 \mathrm{r} / \mathrm{min}, 950 \mathrm{r} / \mathrm{min}$, and $1000 \mathrm{r} / \mathrm{min}$, separately. Similarly, when the concave clearance is set as $20 \mathrm{~mm}$, the speed is set as $1000 \mathrm{r} / \mathrm{min}, 1050 \mathrm{r} / \mathrm{min}$, and $1100 \mathrm{r} / \mathrm{min}$ separately.

TABLE VII. EXPERIMENT CONDITIONS OF THRESHING QUALITY CONTROL STRATEGY OF GRAIN COMBINE HARVESTER.

\begin{tabular}{|c|c|}
\hline Items & Content \\
\hline Model & Zoomlion TB60 \\
\hline Proving Time & June 25, 2018 \\
\hline Agrotype & Wheat \\
\hline Types of Wheat & JingDong 22 \\
\hline Average Crop Density & $0.875 / \mathrm{kg} \mathrm{m}^{2}$ \\
\hline Grain Moisture Content & $8.20 \%$ \\
\hline Stem Moisture Content & $8.49 \%$ \\
\hline
\end{tabular}

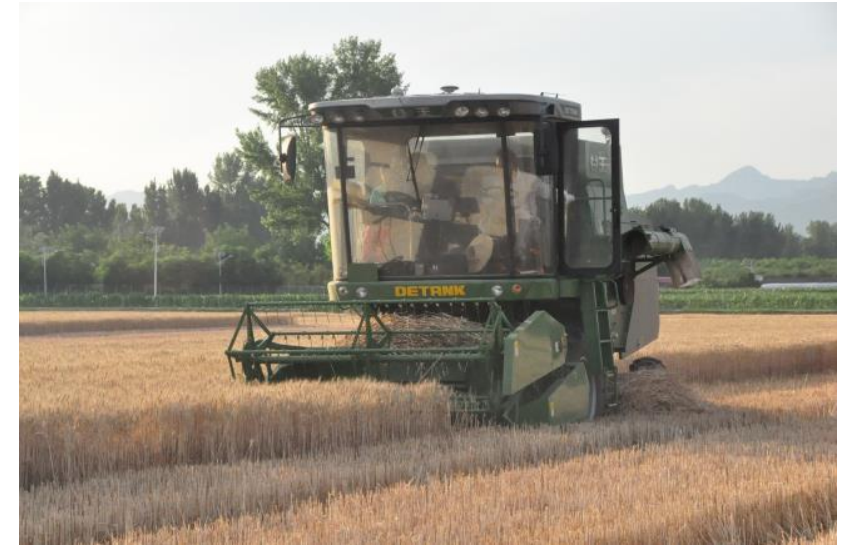

Fig. 12. Experiment site.

From the experiment results, it can be seen that the crashed rate and loss rate of the control experiment has (have?) been reduced to a certain extent. Among them, when the concave clearance is $10 \mathrm{~mm}$ and the rotational speed of the roller is set as $900 \mathrm{r} / \mathrm{min}$, the loss rate and crashed rate decrease the most, and the amplitudes are $44.08 \%$ and $28.23 \%$ separately. When the concave clearance is set as $15 \mathrm{~mm}$, the maximum reduction of loss rate is $31.97 \%$ and the maximum reduction of crashed rate is $25.84 \%$ at $900 \mathrm{r} / \mathrm{min}$ roller speed. When the concave clearance is set as $15 \mathrm{~mm}$, the maximum reduction of loss rate is $31.97 \%$ and the maximum reduction of grain-crashed rate is $25.84 \%$ at $900 \mathrm{r} / \mathrm{min}$ roller speed. When the concave clearance is set as $20 \mathrm{~mm}$, the maximum reduction of loss rate is $27.6 \%$ at $900 \mathrm{r} / \mathrm{min}$ roller speed and the maximum reduction of crashed rate is $29.6 \%$ at $1100 \mathrm{r} / \mathrm{min}$. In summary, the threshing quality control strategy designed in this paper is effective.

Compared with basic data, the loss rate and grain damage obtained by field experiment are not dominant. This is due to uncontrollable differences in grain properties, such as stem moisture content and grain moisture content. The basic data were obtained at $7.90 \%$ grain moisture content and at $8.04 \%$ stem moisture content. The experimental data were obtained under the condition of $8.20 \%$ grain moisture content and of $8.49 \%$ stem moisture content. It has been pointed out that the moisture content has a significant influence on grain damage and loss rate, and with the increase of the moisture content, grain damage and loss rate increase also [7]. However, it can be seen from the experimental results that type-2 FL is better than type-1 FL under the same grain properties.

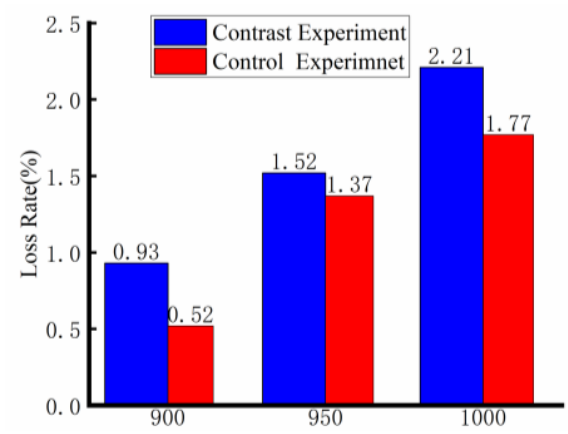

(a)

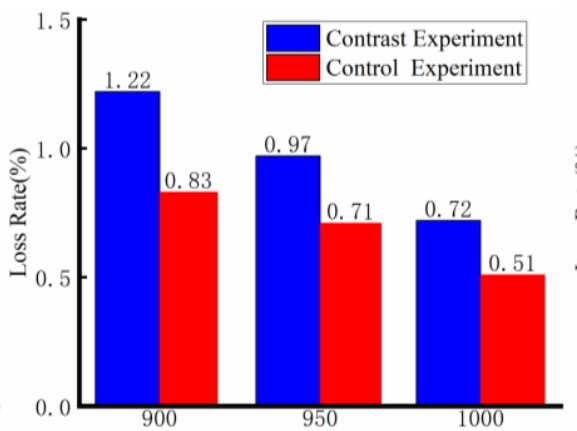

(b)

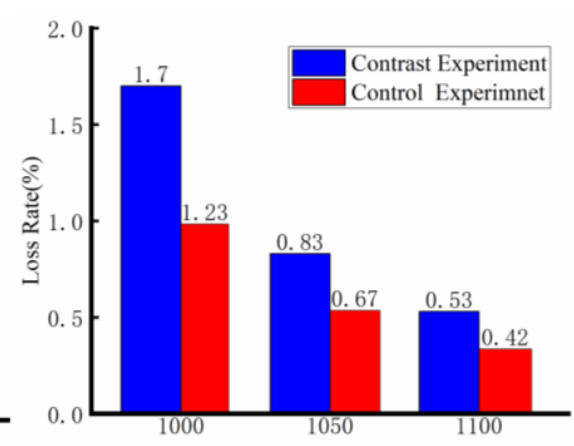

(c)

Fig. 13. Experiment results of loss rate: a) Concave clearance is $10 \mathrm{~mm}$; b) Concave clearance is $15 \mathrm{~mm}$; c) concave clearance is $20 \mathrm{~mm}$.

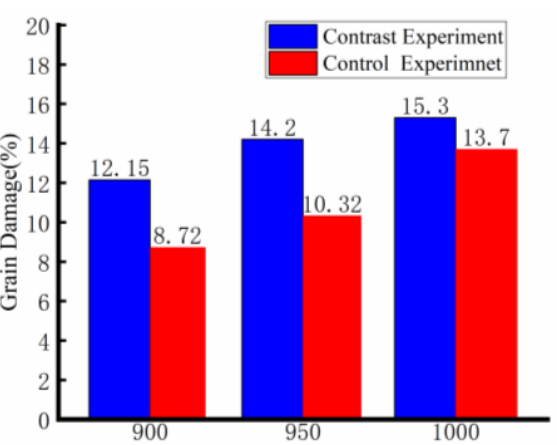

(a)

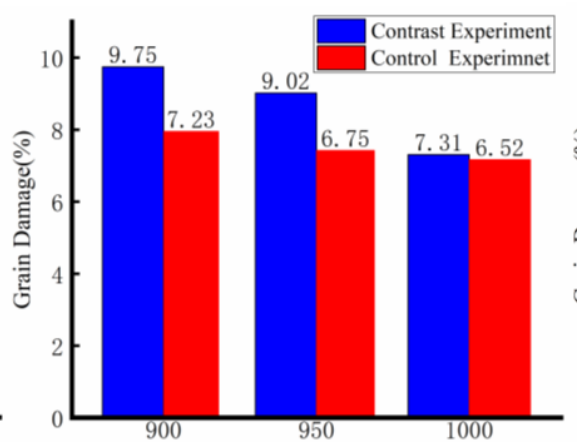

(b)

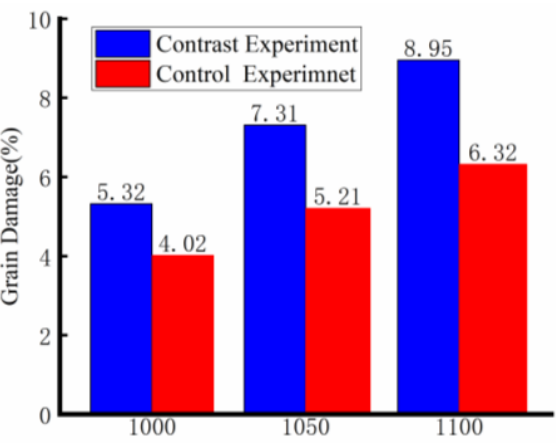

(c)

Fig. 14. Experiment results of grain damage: a) Concave clearance is $10 \mathrm{~mm}$; b) Concave clearance is $15 \mathrm{~mm}$; c) Concave clearance is $20 \mathrm{~mm}$. 


\section{CONCLUSIONS}

1. To design the model of type-2 fuzzy control, combine harvester threshing quality automatic monitoring system is designed in this paper. On this basis, the membership functions of variables and fuzzy control rules of control strategy are proposed.

2. For evaluating the responses of type-2 FLC, type-1 FLC is designed as the object of comparative simulation experiments. The simulation results showed that the ISE and IAE of the type-2 system are lower than those of type1 system under the same input condition.

3 . The field experiment results showed that the type- 2 FLC gives the concave clearance, and the roller speed can significantly reduce loss rate, crashed rate, and improve threshing quality. The maximum reduction of grain damage rate is $44.08 \%$ and the maximum decrease in loss rate is $29.6 \%$.

\section{CONFLICTS OF INTEREST}

The authors declare that they have no conflicts of interest.

\section{REFERENCES}

[1] D. I. Patricio and R. Rieder, "Computer vision and artificial intelligence in precision agriculture for grain crops: A systematic review", Computers and electronics in agriculture, vol. 153, pp. 6981, 2018. DOI: $10.1016 /$ j.compag.2018.08.001.

[2] C. Tania, "Predicting large scale fine grain energy consumption", Energy Procedia, vol. 111, pp. 1079-1088, 2017. DOI: 10.1016/j.egypro.2017.03.271.

[3] T. T. Chen, L. T. Wilson, Qian Liang et al., "Influences of irrigation, nitrogen and zeolite management on the physicochemical properties of rice", Archives of Agronomy and Soil Science, vol. 63, no. 9, pp. 1210-1226, 2017. DOI: 10.1080/03650340.2016.1276286.

[4] J. Fu, Z. Chen, L. J. Han, and L. Q. Ren, "Review of grain threshing theory and technology", International Journal of Agricultural and Biological Engineering, vol. 11, no. 3, pp. 12-19, 2018. DOI 10.25165/j.ijabe.20181103.3432.

[5] X. L. Zhou, R. X. Zhu, X. J. Zhou et al., "The monitoring system for clearing loss of the grain combine harvester based on sensor Technology", Journal of Agricultural Mechanization Research, no. 2, pp. 85-87, 2010.

[6] D. Sun, D. Chen, S. M. Wang, and X. Wang, "A dynamic instability detection and prediction system for high clearance tractor", IFAC PapersOnLine, vol. 49, no. 6, pp. 50-54, 2016. DOI: 10.1016/j.ifacol.2016.10.010.

[7] X. Chen, "Research on the methods and systems for monitoring grain's crushing rate and impurity rate for combine harvester", Ph.D. dissertation, JIANGSU University, 2017.

[8] J. Mahirah, K. Yamamoto, M. Miyamoto et al., "Monitoring harvested paddy during combine harvesting using a machine vision double lighting system", Engineering in Agriculture Environment \& Food, vol. 10, no. 2, pp. 140-149, 2017. DOI 10.1016/j.eaef.2016.12.001.

[9] X. Wang, M. Xu, W. W. Li, B. Miedzinski, S. M. Wang, "Optimal design of lifting platform balance control algorithm co-simulation and experiment", Elektronika ir Elektrotechnika, vol. 23, no. 5, pp. 3-10, 2017. DOI: 10.5755/j01.eie.23.5.19237.

[10] J. Chen, X. B. Ning, Y. M. Li et al., "Fuzzy adaptive control system of forward speed for combine harvester based on model reference",
Transactions of The Chinese Society of Agricultural Machinery, vol. 45 , no. 10 , pp. $87-91,2014$. DOI: 10.6041/j.issn. 10001298.2014.10.014

[11] Z. Qu, D. Zhang, Y. Li et al., "Experiment on feed rate and cylinder speed of longitudinal axial flow threshing and separating device for maize", Transactions of The Chinese Society of Agricultural Machinery, vol. 49, no. 2, pp. 58-65, 2018. DOI: 10.6041/j.issn. 1000-1298.2018.02.008

[12] L. Yang, T. Cui, Z. Qu et al., "Development and application of mechanized maize harvesters", International Journal of Agricultural and Biological Engineering, vol. 9, no. 3, pp. 15-28, 2016. DOI: 10.3965/j.ijabe.20160903.2380.

[13] X. Wang, M. Xu, W. W. Li, H. S. Lu, S. H. Zhang, and S. M. Wang, "Study on orchard vehicle motion stability control system", IFAC PapersOnLine, vol. 49, no. 16, pp. 451-456, 2016. DOI: 10.1016/j.ifacol.2016.10.082.

[14] R. Khir, G. Atungulu, D. Chao et al., "Influences of harvester and weather conditions on field loss and milling quality of rough rice", International Journal of Agricultural and Biological Engineering, vol. 10, no. 4, pp. 216-223, 2017. DOI 10.25165/j.ijabe.20171004.2993.

[15] Equipement for Harvesting - Combien Harvesters - Test Procedure, National Standards of the People's Republic of China GB/T 8097 2008.

[16] M. Louzazni, E. Aroudam, "Control and stabilization of three-phase grid connected photovoltaics using PID-Fuzzy logic", in Proc. IEEE Int. Conf. Intelligent Energy and Power Systems (IEPS), 2014, pp. 279-284. DOI: 10.1109/ IEPS.2014.6874195.

[17] L. A. Zadeh, "The concept of linguistic variable and its application to approximate reasoning-1", Information Sciences, vol. 8, no. 3, pp. 199-249, 1975. DOI: 10.1016/0020-0255(75)90036-5.

[18] D. Andriukaitis, A. Laucka, A. Valinevicius, M. Zilys, V Markevicius, D. Navikas, R. Sotner, J. Petrzela, J. Jerabek, N. Herencsar, D. Klimenta, "Research of the Operator's Advisory System Based on Fuzzy Logic for Pelletizing Equipment", Symmetry vol. 11, iss. 11 , art. no. 1396, p. 1-17, 2019. DOI doi.org/10.3390/sym11111396.

[19] O. Castillo and P. Melin, "A review on the design and optimization of interval type-2 fuzzy controllers", Applied Soft Computing, vol. 12, no. 4, pp. 1267-1278, 2012. DOI: 10.1016/j.asoc.2011.12.010.

[20] M. H. F. Zarandi, A. D. Torshizi, I. B. Turksen, and B. Rezaee, “A new indirect approach to the type-2 fuzzy systems modeling and design", Information Sciences, vol. 232, pp. 346-365, 2013. DOI: 10.1016/j.ins.2012.12.017

[21] J. Aisbett, J. T. Rickard, and D. G. Morgenthaler, "Type-2 fuzzy sets as functions on spaces", IEEE Transactions on Fuzzy Systems, vol. 18, no. 4, pp. 841-844, 2010. DOI: 10.1109/TFUZZ.2010.2046176.

[22] A. Kumar, S. Kundu Manoj Kumar Panda, and V. Kumar, "Designing of an interval type-2 fuzzy logic controller for magnetic levitation system with reduced rule base", in Proc. of 2012 Third International Conference on Computing Communication and Networking Technologies (ICCCNT), 2012. DOI: 10.1109/ICCCNT.2012.6395883.

[23] O. Castillo, P. Melin, and J. R. Castro, "Computational intelligence software for interval type-2 fuzzy logic", Computer Applications in Engineering Education, vol. 21, no. 4, pp. 737-747, 2013. DOI 10.1002/cae.20522.

[24] N. N. Karnik, J. M. Mendel, and Q. Liang, "Type-2 fuzzy logic systems", IEEE Transactions on Fuzzy Systems, vol. 7, no. 6, pp. 643-658, 1999. DOI: 10.1109/91.811231.

[25] O. Castillo and P. Melin, Type-2 Fuzzy Logic: Theory and Applications. Springer-Verlag Berlin Heidelberg, 2008. DOI: 10.1007/978-3-540-76284-3

[26] A. Taskin and T. Kumbasar, "An open source Matlab/Simulink toolbox for interval type-2 fuzzy logic systems", in Proc of 2015 IEEE Symposium Series on Computational Intelligence, 2015. DOI: 10.1109/SSCI.2015.220 